\title{
A New Concept for the Future EHEA
}

\author{
Ann Katherine Isaacs
}

\section{A Time, a Place and a Need for the Bologna Process}

The motivations behind the Bologna Process were many. Indeed, the buildup to the Bologna Declaration (Bologna Process 1999) and its signing must be seen as a polyhedral phenomenon, a multi-faceted confluence of different motivations, experiences and perspectives, many of which continue to underlie and influence subsequent developments. One important factor at the time was the realization that while Europe was becoming increasingly connected, politically and economically, its higher education systems were so diverse that real communication and direct interaction among them were very problematic, or basically non-existent. If the future goal was to be free circulation of goods and people, it was reasonable to hope that, one day, people also would be able to circulate freely to universities anywhere in Europe, and the resulting degrees allow them to seek employment in countries other than that in which they were born or earned their degrees. Another consideration for several countries was the hope that the rapidly growing cohorts of young people desiring a university education would be able to obtain qualifications useful for employment more quickly, thanks to the relatively short time necessary to complete one of the new First Cycle or Bachelor degrees (Isaacs 2006). It was hoped that having an intermediate short-term goal would reduce both the number of dropouts and the number of the many who did not drop out but remained in the system for many years before receiving their degree. After the Sorbonne Declaration (Bologna Process 1998) was signed by four large countries, authorities in central and eastern as well as other western European countries saw the potential benefit of being included in a framework that could coordinate efforts and create a recognizable 'European system', able to compete credibly with American universities (Barblan 2011). The use of credits and a system of sequential degrees would require radical change in most countries but offered the possibility of

\footnotetext{
A. K. Isaacs ( $\square)$

University of Pisa, Pisa, Italy

e-mail: k.isaacs@unipi.it

(C) The Author(s) 2020

A. Curaj et al. (eds.), European Higher Education Area: Challenges for a New Decade, https://doi.org/10.1007/978-3-030-56316-5_24
} 
bringing them into closer communication while allowing and even enhancing their very real cultural and linguistic diversities. The ECTS ${ }^{1}$ pilot project had shown that, although difficult, this was possible, and nearly thirty countries responded to the Italian Minister's invitation to the conference in Bologna that launched the Bologna Process in June 1999.

Notwithstanding the rhetorical success of the idea that universities form a world apart, a realm where universal ideals about expanding human knowledge without regard for national borders hold sway, historical reality has been very different, especially in recent centuries. European universities as they existed in the 1990s were products and also among the creators, shapers and supporters of nation states, national cultures and national literatures as well as national economies and, when required, national war efforts. Nineteenth and twentieth century European universities had the legitimate task of educating their national elites and preparing their bureaucracies, and they often became important actors in formulating competitive and even divisive national projects and visions.

Before the official beginning of the Bologna Process, the Magna Charta Universitatum (1988) and the Lisbon Recognition Convention (Council of Europe/UNESCO 1997) aimed to bring the connected and international character of higher education back to the fore and to give it reality by breaking down the barriers built up over time around separate national systems.

It was not by chance that an initiative such as the Magna Charta Universitatum looked back to the pre-national Middle Ages and to Renaissance Humanism, when supposedly there had been a connected intellectual world of scholars and scholarship, and where 'international mobility' in pursuit of knowledge, collaboration and sharing was a given. To what extent this imagined reality corresponds to historical fact is not important here. Rather, the vision of an ideal past, based on the University of Bologna as the Alma Mater Studiorum, the Nourishing Mother, and a template for all universities, furnished a useful model and inspiration for a more open future, as did Erasmus of Rotterdam, an example of an accomplished and tolerant Humanist scholar and teacher, Latin-speaking and writing, able to travel from one part to another of a Europe until it was divided by the Reformation. Hence the relevance and resonance of ERASMUS, the well-chosen acronym for the longwinded "EuRopean Community Action Scheme for the Mobility of University Students".

Most of the higher education systems existing in the European Union at the time of the signing of the Treaty of Maastricht (1992) had roots not so much in the Middle Ages as in the French Revolution and its aftermath: the Napoleonic founding of the Imperial University, its breakup, and the numerous subsequent creations connected with national unifications, awakenings, and re-awakenings - up to and including those following the demise of the USSR (Gerbod 2004; Rüegg and Sadlak 2011). There were exceptions, of course, and in many cases, traditional aspects

\footnotetext{
${ }^{1}$ European Credit Transfer and Accumulation System, originally established as the European Credit Transfer System (hence the abbreviation) in 1988. For an overview, see https://ec.europa. eu/education/resources-and-tools/european-credit-transfer-and-accumulation-system-ects_en, accessed 20 January 2020.
} 
inherited from a previous age subsisted. But in recent centuries, most universities, whether traditional or innovative in their academic organization, were dedicated to the fashioning and the promulgation of a national culture, literature and language, rather than - or in any case, in addition to - the more general ideal of the development of knowledge for the sake of all humankind. Today's Humboldt University (so named only in 1949) was indeed founded by Wilhelm von Humboldt, giving rise to the much cited but varied and even contradictory images of the 'Humboldtian university' (Östling 2018); he did so however in 1809, as head of the Directorate of Education, a subsection of the Prussian Ministry of the Interior, and the result, the Friedrich-Wilhelm University, was part and parcel of an intensive state-building program.

One result of their history and strong links to and dependence on governments was that European higher education systems were organized in national contexts, on the basis of national legislation, and under the authority and often the firm control of their Ministries of Education. Traditions differed with regard to the extent and nature of academic freedom, financial and academic autonomy, the structure of studies, the status of professors, and much more. Nonetheless, and it seems relevant in the present context, in almost all countries, few universities could do much to modify or adapt their curricula, to update them or to change their teaching methods radically, without the consent of or even orders from their Ministries.

The principles declared to lie at the base of the Sorbonne and Bologna agreements were, inter alia, the fundamental values of academic freedom and institutional autonomy, but not only those. More broadly, we might say that the inspiration, since the time of the Sorbonne Declaration and before, was to proclaim and make real the knowledge that higher education has a duty to provide for society and the world, underlining its character as an autonomous international space where freedom of expression, scientific and intellectual endeavour and the education of young human beings and citizens can take place in an optimal way, beyond national borders-indeed using the possibilities of mobility to enhance critical understanding. To accomplish this, however, clearly the commitment of governments was essential.

The first two decades of the Bologna Process have often placed at its centre the very necessary changes agreed by the member countries in order to create compatible systems of studies and to facilitate communication and transparency among them. This work is ongoing and needs to be completed. However, we now must attempt to visualize the future steps.

\section{Towards the Future}

Since the Bologna Declaration was signed, there have been numerous important changes in the ways universities connect with and reach out to society, not only in their local and regional areas. At the same time, we have become more aware of the limits that our common efforts, conceived in a more optimistic era, may encounter because of new political, economic and societal challenges. 
The celebrations for the twentieth anniversary of the signing of the Bologna Declaration were joyful, as well as thoughtful, and brought together many of the protagonists and interested parties to evaluate what has been accomplished. ${ }^{2}$ That moment of enthusiasm gave new life to the idea of the EHEA, which in some quarters has come to be seen with ennui, if not open hostility. The Bologna Process received and deserved a shot in the arm, stimulus to go forward resolutely. At the same time, its supporters asked themselves how to preserve this new level of energy and aspiration. New objectives? Measurable targets? Or is it better to concentrate on existing commitments, hoping to arrive at full compliance in all countries within a relatively short time?

Many concluded that 2030 is an appropriate target date for reaching another level of progress in the Bologna Process. The obvious place to make manifest future goals is the Ministerial Conference to be held in Rome in $2020 .^{3}$ On that occasion, it would be useful for the Ministers to propose and commit their countries to new goals in order to motivate and strengthen cooperation among the countries, organizations, institutions and stakeholders involved in the future development of the EHEA.

\section{A European Higher Education System?}

The first such possible goal publicly proposed for discussion was to have in place a European Higher Education System by 2030. This idea was propounded by Michael Murphy, newly elected president of the EUA, at the Bologna Celebration itself, and on other occasions. Exactly what Murphy intended and why he proposed it with such vigour seems quite clear: "We need to ensure that the European higher education system acquires a world-wide degree of attraction equal to our extraordinary cultural and scientific traditions". In other words, the European higher education must be able to represent itself as one, as a single 'system', able to compete with other 'systems'. In fact, he added, "It is time to examine what was meant by 'European higher education system' and what that system must look like if Europe is to be one of the four or five large geopolitical regions defining global economic, political, cultural and societal norms during the 21 st century. [...] We must design a comprehensive system including all universities in deep transnational networks, harvesting and coordinating excellence across the continent". 4

This proposal reminds us that in Europe excellence does not mean elitism but rather excellence formed through cooperation of diverse institutions and cultures in a guaranteed framework. Nonetheless, the central message is competitive and

\footnotetext{
${ }^{2}$ See http://bolognaprocess2019.it/, accessed 20 January 2020.

${ }^{3}$ See http://www.ehea.info/page-ehea-ministerial-conferece-rome-2020, accessed 20 January 2020.

${ }^{4}$ https://eua.eu/resources/expert-voices/121:the-bologna-process-look-back,-snapshot-andforesight.html; see also https://www.youtube.com/watch?v=xy0h613cho4\&feature=emb_title, both accessed 20 January 2020.
} 
focuses on the need for a "system" in order to represent European higher education effectively in a competitive world. We are invited "to champion the creation of a 'European University System' that will partner with and compete successfully with those emerging in the other great regions of our world [...] Europe's universities must be the powerhouses of European creativity, innovation and success" and, hence, to give stronger support to European higher education institutions "they must be networked, resourced, autonomous, accountable and free to be so". 5

The proposal encountered mixed reactions. It was generally understood, perhaps somewhat out of context, to mean that the basic rules of the EHEA have been long established and that it is high time to ensure that they are applied fully by all member countries. It is significant that this was understood as the only way of establishing a 'system', respected (and enforced) by all in such a way that studies carried out in any EHEA higher education institution would be recognized by all the others, and so that a compact EHEA could make its presence felt around the world. Such an idea immediately clashes with the fact that there is no public authority at European level competent for the formal organization of education provision and gives rise to the fear that such an authority might be needed, desired or somehow imposed.

The mention of "deep transnational networks" suggests a somewhat different strategy: it points towards the idea that 'groups of Universities', such as those cooperating in the new Erasmus+ European Universities alliances, will be induced to pressurize their governments into completing the tasks set by the EHEA so that the planned cooperation can indeed take place (for example, on joint degrees, as well as the seemingly more complex questions of transferability of tenure and the like). This understanding of the function and the possible effects of the European Universities scheme appears to be aligned with the hopes of the European Commission that the alliances will push forward the 'automatic recognition' agenda, and in general induce countries to take their EHEA commitments more seriously. ${ }^{6}$ It is true that if the European Universities alliances are to have such powerful effects on the shape of the EHEA, it will be necessary at the very least to include the member countries not considered 'Programme countries' in the European Universities calls.

\footnotetext{
${ }^{5}$ Ibid.

${ }^{6}$ Inter alia, according to the Erasmus+ Programme Guide 2020, p. 126, "European Universities" are expected to commit, "in cooperation with their national authorities [...] to work towards relevant policy objectives of the European Education Area, such as: multilingualism; automatic recognition of academic qualifications and learning periods abroad provided for by the participating higher education institutions within the alliance [...] as well as the Bologna key commitments (quality assurance, recognition, and wherever applicable three cycle degree [sic])": https://ec.europa.eu/ programmes/erasmus-plus/resources/programme-guide_en, accessed 31 March 2020.
} 


\section{Discussions, Consultations and Debates Promoted by the BFUG}

In any case, the idea that achieving the "Bologna dream" will require a new level of commitment and imagination is widespread, and within the BFUG substantial and interesting efforts have gone into investigating what form the future goals might have. The Paris Communiqué mandated the BFUG to develop further the priorities for the future of the EHEA (Bologna Process 2018). This mandate led to a series of initiatives: first to a consultation among the members of the $\mathrm{BFUG}^{7}$ then to a discussion in breakout groups in the BFUG meeting in Bucharest in April 2019, ${ }^{8}$ then to asking all countries and all consultative members and partners to conduct consultations among their stakeholders or members, ${ }^{9}$ and finally again to breakout sessions at the November 2019 BFUG meeting in Helsinki. ${ }^{10}$

Much of the discussion has focused on whether it is possible to develop an overall vision of the future of the EHEA which can tie together and give coherence to the many priorities and dimensions of the EHEA and the various directions that members and non-members think it should take in the future. It is planned to put the results of the national and organizational consultations carried out in the last half-year on the ehea.info website: the material is abundant and complex, and its study will yield interesting insights into the many-faceted concerns and proposals of the European higher education world. ${ }^{11}$

\section{Which Vision? Whose Vision?}

In Bucharest (April 2019), the BFUG dedicated the central part of its meeting to the discussion in breakout groups of a concept note ${ }^{12}$ which asked them to envision the future world and to imagine the challenges such a world would pose to higher education. The results confirmed many of the existing priorities as continuing to be meaningful in the coming decade. More importantly, it drew an image of a rapidly changing technological, social and economic context, in which the needs for higher

\footnotetext{
${ }^{7}$ Online survey on the governance and thematic priorities of the EHEA after 2020: http://www. ehea.info/page-governance-thematic-priorities-after-2020, accessed 20 January 2020.

${ }^{8}$ Preparatory Note, Bucharest BFUG meeting, 4-5 April 2019: http://www.ehea.info/Upload/65_ BFUG_meeting_Bucharest/BFUG_RO_MK_65_9_3_Breakout_sessions.pdf, access- ed 20 January 2020 .

${ }^{9}$ Materials for the Consultations, July - October 2019: http://www.ehea.info/page-governancethematic-priorities-after-2020, accessed 20 January 2020.

${ }^{10}$ Helsinki BFUG meeting, 12-13 November 2019: http://www.ehea.info/page-BFUG-meeting67, accessed 20 January 2020.

${ }^{11}$ The materials on a restricted area of the www.ehea.info website, are available at present only to BFUG members.

${ }^{12}$ Preparatory Note, Bucharest BFUG meeting, see above, note 8 .
} 
education may be strikingly different than in the past and at present. In this view, in the near future, and to an extent not yet realized by the higher education community, people at all stages in their lives will need and desire 'updates', new competences of various kinds, necessary for their professional or personal development. This vision of the future suggests that higher education institutions will no longer be able to focus exclusively, or nearly so, on offering complete 'sequential' degree programs. Rather they will need to provide smaller pieces of learning, such as are already being offered by other providers.

This vision suggests that greater flexibility will be necessary, in the sense that people must be able to go where they want in order to build the competences they need, and they must be able to do this when they want or need to. This requirement in part coincides with the original inspiration for the Bologna Process, the idea of removing barriers in order to allow circulation of students and staff to institutions in other countries. It is more radical, however, in that it suggests a widespread need for new kinds of learning, often in a virtual or open context, and a change in focus. Lifelong learning may no longer be a kind of extra with respect to normal curricular studies, but rather the core business of higher education institutions, or at least an important part of it. This has also led to the proposal of offering 'micro-credentials' (e.g. Gallagher 2019), understood in the EHEA context to be 'pieces of learning' corresponding to 3 to 5 ECTS credits. Innovative projects are now starting to elucidate the issues connected with micro-credentials, including their 'stackability', or how to manage their accumulation and recognition.

The question naturally arises as to whether the existing structural elements and transparency and quality tools (the correct use of which form the current "key commitments" for the EHEA members) will continue to have their central role. The understanding of the BFUG discussion groups is that some adaptation may be necessary, but the basics - the Qualifications Framework and ECTS, the Diploma Supplement, the Lisbon Recognition Convention, and the European Standards and Guidelines for quality assurance - will continue to constitute the foundation blocks of the EHEA.

\section{A European Higher Education Community?}

After the successful Bucharest discussion on the vision of the future, and in parallel with the national consultations, similar discussion groups were held during the Helsinki BFUG meeting in November 2019. In this case, the 'vision' theme was proposed from a different perspective. Members were first invited to describe the future they would like to see for European higher education in 2030 and beyond, then to focus on how to describe the desired future in a motivating way, and finally 
to look at whether the concept of a "European higher education community" could be useful. ${ }^{13}$

The vision for the future of the EHEA that emerged appeared to be a situation where all people in the EHEA (not only citizens, an important distinction) can access, on fulfilment of the necessary formal requirements, whatever level of education they desire; where people coming from disadvantaged backgrounds are not only permitted to access higher education, but encouraged and supported in developing the necessary aspirations and qualifications; and where their education provides not only competences useful for employment, but also those necessary for civic and social life, and personal culture. Inclusiveness, greater diversity, closer dialogue with other regions of the world, enhanced mobility are features of this vision, on which all appear to agree. To sum up, we can register support for a vision of higher education which should strive to serve the four purposes specified in the Council of Europe's 2007 Recommendation on the public responsibility for higher education and research, which should include preparation for sustainable employment, for life as active citizens in democratic societies, personal development, and the development and maintenance, through teaching, learning and research, of a broad, advanced, knowledge base (Council of Europe 2007). We may note that in past Communiqués the first purpose has often been highlighted, the second and the third have received at least lip service; whereas the fourth has perhaps been taken too much for granted, as something that higher education institutions simply do, as part of their normal modus operandi.

This goal or vision is based on optimism and a 'Yes, we can' approach, since clearly the EHEA faces unprecedented challenges. The positive, optimistic, idealistic, and even unrealistic aspect of this vision includes placing at the forefront the United Nations Sustainable Development Goals. ${ }^{14}$ In this case, too, the ambition is to commit higher education institutions to use their research, educational and outreach capacities fully to contribute to reaching those goals by 2030 .

Numerous countries and organizations, when asked to describe their vision in the consultations, emphasize the need for greater involvement of higher education institutions, both in formulating recommendations and in implementing them. The social dimension of higher education and the need for autonomy and better preparation of teachers are often mentioned, as is the need to adapt to a changing world. The importance of digitalization, both as a challenge and a resource, is underlined. Innovative teaching methods and learning activities should take advantage of the opportunities opened by new technologies, on the one hand, while on the other, higher education institutions must respond to the growing need for digital and advanced technological competences. ${ }^{15}$

\footnotetext{
${ }^{13}$ Concept Note: Future of the EHEA -Thematic discussion on vision and priorities, Helsinki BFUG meeting, 12-13 November 2019": http://www.ehea.info/Upload/BFUG_FI_TK_67_7_2_ Introduction_breakout_sessions.pdf, accessed 20 January 2020.

${ }^{14}$ https://www.un.org/sustainabledevelopment, accessed 20 January 2020.

${ }^{15}$ See above, note 11 .
} 


\section{Do We Need a New Guiding Concept?}

On many aspects of the future goals or the vision for an EHEA for the coming decades, there is a good degree of consensus among BFUG members. No one doubts the necessity of implementing the existing "key commitments" effectively and in all countries. These are important results of the elaboration carried out during the previous two decades to address the most obvious imperatives: that the basic structures of the degree programs should be the same; that those structures be organized in terms of student workload based credits as a measure of 'volume of learning' and level of learning outcomes; that delivery should be internally and externally monitored, enhanced and guaranteed by independent agencies according to agreed guidelines; that individual learning accomplishments should be recognized: first of all described according to a common format (the Diploma Supplement), and then considered credible in all the other EHEA countries. Potentially, they lead to 'automatic recognition': once again a concept which can be interpreted in different ways, but that, in essence, means reaching a situation where within the EHEA, all EHEA credentials can be accepted as easily as if they were presented in the country of the institution that issued them.

The vision is, in the first place, of an EHEA in which the decisions already taken, the commitments made, and the solutions already developed in the EHEA are implemented, and in such a way that smooth and easy communication can actually take place. This is the bedrock reality, on which innovation and higher future achievements are to be built.

In its essence, the EHEA of the future should be a place where values are upheld, rules are respected, and there is a closer collaboration between public authorities (at ministerial level) and higher education institutions, staff, students, administrators, employers and their hinterland. This seemingly simple image is complicated by a number of factors. In several countries the fundamental values are challenged; many countries are prima facie compliant with the key commitments to structural reform but in ways that are either formally or practically different from those of their neighbours; the BFUG and the EHEA itself, being based on a voluntary intergovernmental structure, often do not make efficient use of the energies and expertise expressed by the higher education world and are under little pressure to do so. In addition, values, tools and rules defined in the course of the past decades will need at the very least substantial re-elaboration to adapt them to existing and future challenges and opportunities and to ensure that students and higher education stakeholders are involved in this process and supportive of it.

Over the last twenty years, the Ministerial Communiqués have become somewhat standardized and often repetitive. Without the monitoring activities, it would sometimes be difficult to tell from the Communiqués themselves whether anything has been accomplished and, if so, what. In many countries, few people except for staff nearing retirement remember the pre-Bologna system. This in itself creates misunderstandings, insofar as younger staff and, naturally, students are unaware of what the previous situation was and are unable to visualize the telluric changes that the 
Bologna Process has triggered. As a result, even some of the obvious obligations deriving from the Process (e.g. updating course catalogues, using grade distribution tables, responding to quality assurance procedures based on the ESG) are often understood as useless bureaucratic complications, rather than as keys to making EHEA-wide cooperation work smoothly for the benefit of all.

It is important to consider how the positive, progressive, beneficial and necessary features of the process can be communicated better to those who should benefit directly by them, and/or must carry them out.

\section{Which Concept?}

The BFUG Board appears to concur that the 2020 Communiqué should be a document that people around the world can read and easily understand. The language should be simple, not simplistic, and the arguments built up in a clear way. It has also been suggested that a simple and powerful image be proposed as an overarching and inspiring goal, to help motivate and guide complex efforts over the next ten years. ${ }^{16}$

As mentioned, the first suggestion was to aim to build a "European Higher Education System". A second, in part contrasting, proposal was to build a "European higher education community". The relations between the two, and with the present "European Higher Education Area", need to be carefully considered, as the implications of the choices to be made are relevant.

Both the 'system' and the 'community' seem to have been originally understood in analogy to the goal stated in the Bologna Declaration of working for a "European area of higher education", which eventually had the result that in 2010 the Area was deemed to exist, and the acronym EHEA became official with the BudapestVienna Communiqué (Bologna Process 2010). In other words, the idea that sparked off the current discussion was to propose that during the coming decade the 'Area' should become something different, more specific, stronger and more effective than at present, and that by 2030 both the reality and the name should be changed. Organizing efforts in order to achieve the reality indicated by the proposed new name was seen as a lever for fulfilling the potential of the EHEA, allowing it to reach its objectives more effectively.

Doubts and even strong opposition to one, the other, or both hypotheses were quickly expressed.

With regard to the "system" hypothesis, the objections are that the EHEA is based on a voluntary consensual agreement between governments which does not lend itself to deciding on a single "system", for which there would be no single competent public authority, and which, hence, it would be unable to enforce or regulate, and which in

\footnotetext{
${ }^{16}$ This was discussed at the Istanbul Board meeting, 24 September 2019, Minutes, point 4.3: www. ehea.info/Upload/BOARD_FI_TK_66_Minutes.pdf, accessed 20 January 2020.
} 
any case would limit the diversity between national 'systems' — still a feature, and a very valuable one, of the European Higher Education Area. It has been pointed out that the word 'system' is already found in the Bologna Declaration, but clearly, there is a big difference between a rather casual reference to 'system' when the Bologna Process was taking its first steps and a full-fledged plan to turn the EHEA into an EHES.

The objections to "community" seem to be less fundamental with regard to the substance of the proposal: the idea that the EHEA needs to be more cohesive, inclusive and foster a more positive and functional relationship with the higher education world and society in general is widely accepted and appears in many of the documents resulting from the national consultations. Most doubts focus on the fear that people will be confused if there is a change of name; the EHEA acronym is well-known in some ambiences, and at least some people are aware in a general way of what it stands for. Any change of acronym would destroy this level of awareness without creating particular benefits.

Some documents have been elaborated and informally circulated among members of the BFUG Board in order to discuss whether and how the various concepts of 'Area', 'system' and 'community' — with or without capital letters — might be used separately or together, insofar as they indicate or emphasize different aspects or desired features of the future EHEA.

For example, in "A Goal: The European Higher Education Community?" the present author suggested the following relationship between these key elements:

- In the Bologna Process (1999), we already find the expressions 'Europe of Knowledge'; 'common social and cultural space';- 'European labor market'and 'European area of higher education' (which eventually became the goal for 2010). Now we are in search of a concept or image which can motivate people, institutions and governments, in carrying the Process forward for the next decade and beyond. The suggestion has been made to aim for a "European Higher Education System". This expression seems to imply ensuring that all the agreed rules and tools actually work smoothly (i.e. are actually implemented in all EHEA countries, and hopefully in similar and compatible fashion)—which in itself would be a worthy objective.

- There are however a number of further 'dimensions' which have often been described and advocated, but which may not have become a part of the thinking and sensibility of the broader higher education community and society at large. Great attention must be given in the coming decade to developing a more flexible, competence-, work- and research-based higher education world.

- Thus we might see the "European Higher Education Area" as comprising the geographical space occupied by the current and future members of the EHEA, presumably all signatories of the ECC. ${ }^{17}$

- The objective for 2030 could be to build, within this space, a "European Higher Education Community"- a more complex task, which would place at the fore-

\footnotetext{
${ }^{17}$ European Cultural Convention (author's note).
} 
front the aspects of inclusion, participation and collaboration of the entire higher education world - ministries, organizations, networks, universities and other HEIs themselves, students staff, teachers and researchers - and the societies which they serve and in which they are embedded.

- This "European Higher Education Community" would be built within the "Area", with links to other Areas (world macro-regions); it would be founded on shared values (fundamental values, not only of an academic nature) and on the "European Higher Education" necessary to ensure transparency, recognition and mobility (freedom of students to choose). It would be crisscrossed by the links formed by European Universities, Joint Degrees, a high level of mobility for education and training. It would create strong links with schools of all levels, with employers, and would enable citizens to be and become learners at all ages, according to their needs. ${ }^{18}$

In this version, the EHEA as an acronym and general name would continue to exist and define the two-dimensional 'space' in which the official members are located. The 'system' would define the common elements which, properly implemented, allow smooth flows from country to country and from institution to institution. 'System' would also allow European higher education institutions to represent themselves on the world scene as a cohesive whole, which would be useful from the point of view of international competitiveness (and transparency). 'Community' would indicate the kind of 'society' that should emerge in the 'Area': a multifaceted, diverse, responsive, inclusive 'area' where cooperation and solidarity are keynotes, and where peer support at all levels is practiced in the interests of all. Where students, employers, employees, academics and ministries can speak to each other and be heard because they are working for common goals.

\section{And What About...?}

The next questions might be: are there specific reasons for refusing the 'system' word and/or the 'community' word? Are they in contrast or conflict with the 'area' word?

As mentioned, 'system', at least when capitalized, proves worrisome for many countries because of its overtones of regulation and coercion and the implication that there should be a single competent authority in Europe. 'System' per se, as used in several disciplinary contexts, does not necessarily entail an imposition of rules by an authority. In the social sciences, it is rather an empirical way of understanding complex interactions understood as taking place largely if not exclusively within certain boundaries. Thus, a 'world system' can include the entire world or a part of it: the definition of 'world', in this case, being that most (not all) of what is relevant takes place within it. Interestingly, during the discussions that took place in Helsinki

\footnotetext{
${ }^{18}$ Informal note, circulated during the Istanbul BFUG Board Meeting, 24 September 2019: http:// www.ehea.info/Upload/BOARD_FI_TK_66_Minutes.pdf, point 4.3, accessed 20 January 2020.
} 
in November 2019, one BFUG member (by profession a chemist) asked whether 'community' could be understood as an ecosystem. Indeed, in the natural sciences, 'system' (and 'ecosystem') has a descriptive function rather than a regulatory one. However, inevitably, "education system" implies clear and certain boundaries and a responsible public authority.

"Community" is widely, but not universally, understood to be something that symbolizes participation, sharing or belonging. To the historian or social scientist, it is likely to suggest a complex, often urban, society including forms of (self) government, agreed rules, diverse social groups, social, economic, political and artistic activities, not necessarily closed. However, one discussant said that when he thought of community, he visualized the closed or 'gated' communities that have become common in some parts of the world, particularly to protect the wealthy from unwanted contacts with the rest of society. For an EHEA that wants to become more and more inclusive and for its student body to reflect more and more closely the social, economic and ethnic/linguistic composition of the population, such an understanding, if general, would eliminate 'community' from the running. Fortunately, this does not seem to be a widespread reaction.

The problem of the degree of openness with respect to the rest of the higher education world must be resolved on its own terms, whether the guiding concept is Area, system, or community. Interestingly, some of those opposed to replacing Area with community motivate their opposition with the idea that the 'Bologna Area' should not be closed and suggest that the future relationship with countries and institutions that declare their desire to comply with Bologna, but are not eligible to become members, could be considered part of a broader a 'Bologna community'. This idea has not yet been discussed in the BFUG, but prima facie offers a novel and stimulating perspective.

A further question is whether any of the terms under discussion have negative valences when translated into other languages. A cursory examination of the usual (and many of the unusual) translations proposed by Google in all the national languages represented in the BFUG suggests that most have versions of 'system' and of 'community' that derive from Latin or Greek, although in many cases there are other possible translations which have a different root, or a different basic meaning. Some resonances may be negative ('common' itself can mean low quality or vulgar, as well as shared or frequent), but so far in discussions, it appears that understandings of 'system', ' 'community' and 'area' depend more on professional training than on national or regional understandings.

\section{To Conclude}

Discussion will continue in the coming months. A closer study of the material produced in the national consultations may provide further insights and guidance.

The concepts proposed to encapsulate and symbolize the future form of the EHEA convey quite different ideas, which, although not necessarily incompatible, 
emphasize certain directions of development rather than others. At its beginning, the Bologna Process responded to numerous, at times contradictory, expectations and needs. In the coming decade, once again, it will be necessary to indicate a broad path forward, describe the landscape through which it must pass and the objectives to be reached. Again, it is reasonable to imagine that understandings and motivations will be varied and even contrasting, but areas of agreement, confluence and consensus can be found.

We may ask whether the Bologna Follow Up Group in its present configuration will be able to guide this process effectively. In the years immediately preceding and following the signing of the Declaration, there were more varied forms of direct involvement of the academic community. Bologna Seminars, Thematic Networks and Tuning and other forms of transversal interaction brought together academic experts and subject area groups of academics committed to developing European higher education in new ways. The BFUG was not yet consolidated as the place where representatives of ministries and certain key organizations were expected to guide and guard the Process. During the round of consultations on the future priorities in view of 2030, the BFUG has felt the need to reach out to the academic community and to the other higher education stakeholders in a more open way.

The beauty and the value of the European Higher Education Area will not be found by guaranteeing internal uniformity, nor in the EHEA becoming a direct rival or imitation of other world systems. Rather, they will lie in the unique and difficult enterprise of coordinating, enhancing and connecting very different cultural, linguistic, scientific and organizational realities by means of broad agreed guidelines. European higher education systems and institutions, precisely because of their diversity, offer unprecedented opportunities for creating knowledge and competences, forming abilities and skills, and developing capacity for autonomy of judgement and social responsibility (Isaacs and Sticchi-Damiani 2003). Europe and the EHEA are not founded on uniformity, nor on an ideal of uniformity, but rather on the lucid realization of the value of difference and the necessity of agreement in order to protect it and benefit from it.

Mobility of individuals, creation of shared projects and programs, inclusion, outreach: all are factors which enrich our peoples-if our countries and higher education institutions are connected in contexts of freedom, democracy, citizenship and awareness of and openness to the wider world. Such ideas and ideals inspired the Bologna Process, but to realize their full potential further agreement, action and hard work will be needed.

In the view of this author, re-establishing strong and direct links with the academic world itself will be necessary if the Bologna Process is to move forward. The key role of motivated academics (teachers and researchers) in giving substance to the EHEA must be recognized and supported. The support, knowledge and creativity of all stakeholders-learners first of all, higher education institutions themselves, local authorities, employers — will be needed to reach the goals for 2030. This realization underpins the concept of community.

The author hopes that the Area can become the centre and the foundation of a European higher education community and that the community's borders will 
encompass and connect a larger space than those of the present Area. If deemed opportune, the EHEA acronym may be retained, but the broad path forward should include commitment to making the 'system' work, by ensuring adhesion of its many component 'systems' to the agreed guidelines, while building a connected, inclusive, cohesive and polyhedral community by 2030 .

\section{References}

Barblan A. (2011). From the University in Europe to the Universities of Europe. In Rüegg W. (Ed.), A History of the University in Europe (Volume IV, pp. 530-574). Cambridge: Cambridge University Press, Epilogue.

Bologna Process (1998). Sorbonne Joint Declaration Joint declaration on harmonisation of the architecture of the European higher education system by the four Ministers in charge for France, Germany, Italy and the United Kingdom Paris, the Sorbonne, May 25 1998: http://ehea.info/media.ehea.info/file/1998_Sorbonne/61/2/1998_Sorbonne_Declaration_ English_552612.pdf, accessed 11 February 2020.

Bologna Process (1999). The Bologna Declaration of 19 June 1999. Joint declaration of the European Ministers of Education: http://ehea.info/Upload/document/ministerial_declarations/1999_ Bologna_Declaration_English_553028.pdf, accessed 11 February 2020.

Bologna Process (2010). Bucharest-Vienna Declaration on the European Higher Education Area, 12 March 2010: http://www.ehea.info/Upload/document/ministerial_declarations/Budapest_ Vienna_Declaration_598640.pdf, accessed 20 January 2020.

Bologna Process (2018). Paris Communiqué, 24-25 May 2018: http://www.ehea.info/Upload/ document/ministerial_declarations/EHEAParis2018_Communique_final_952771.pdf, accessed 20 January 2020.

Council of Europe/UNESCO (1997). Convention on the Recognition of Qualifications concerning Higher Education in the European Region: https://www.google.com/search?client=firefox-b-e\& q=lisbon+recognition+convention+pdf, accessed on 20 January 2020.

Council of Europe (2007). Recommendation of the Committee of Ministers to Member States on the public responsibility for higher education and research): https://www.coe.int/t/dg4/ highereducation/News/pub_res_EN.pdf, accessed 20 January 2020.

Erasmus+ Programme Guide (2020): https://ec.europa.eu/programmes/erasmus-plus/programmeguide/part-b/three-key-actions/key-action-2/european-universities_en, accessed 31 March 2020.

Gallagher, S. (2019). A new era of microcredentials and experiential learning. University World News. 15 February 2019: https://www.universityworldnews.com/post.php? story $=20190213103113978$, accessed 20 January 2020.

Gerbod, P. (2004). Relations with Authority. In Rüegg W. (Ed.), A History of the University in Europe: Vol. III. Universities in the Nineteenth and Early Twentieth Centuries (Chapter 3, pp. 83-98). Cambridge: Cambridge University Press.

Isaacs, A.K. (2006). Introducing the Bachelor (Bologna First Cycle Degree). In E. Froment et al. (Eds.), EUA Bologna Handbook. Making Bologna Work, section C.4.2-1, Berlin-Stuttgart: Raabe, http://www.bologna-handbook.com/index.phpoption=com_docman\& task=doc_details\&gid=136\&Itemid=50; currently available in The Best of Bologna - Handbook, vol. 16, Berlin: DUZ Academic Publishers, https://shop.duz-medienhaus.de/best-of-thebologna-handbook-volume-16-printed-version.html, accessed 20 January 2020.

Isaacs, A.K. \& Sticchi-Damiani, M. (2003). Knowledge and Competences for a New World: European Universities in the 21st Century. In Cuadernos de Deusto (29, pp. 111-132). also available at: https://dialnet.unirioja.es/ejemplar/89086, accessed 20 January 2020. 
Östling, J. (2018). Humboldt and the Modern German University. An Intellectual History. Lund: Lund University Press; translation by Lena Olsson, of Östling J. (2016), Humboldts Universitet: Bildning och vetenskap i det moderna Tysklands historia, Stockholm: Atlantis.

Rüegg, W. \& Sadlak, J. (2011). Relations with Authority. In Rüegg, W. (Ed.), A History of the University in Europe (Volume IV, Chapter 3, pp. 73-203). Cambridge: Cambridge University Press.

Open Access This chapter is licensed under the terms of the Creative Commons Attribution 4.0 International License (http://creativecommons.org/licenses/by/4.0/), which permits use, sharing, adaptation, distribution and reproduction in any medium or format, as long as you give appropriate credit to the original author(s) and the source, provide a link to the Creative Commons license and indicate if changes were made.

The images or other third party material in this chapter are included in the chapter's Creative Commons license, unless indicated otherwise in a credit line to the material. If material is not included in the chapter's Creative Commons license and your intended use is not permitted by statutory regulation or exceeds the permitted use, you will need to obtain permission directly from the copyright holder.

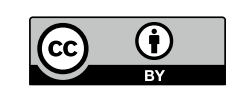

